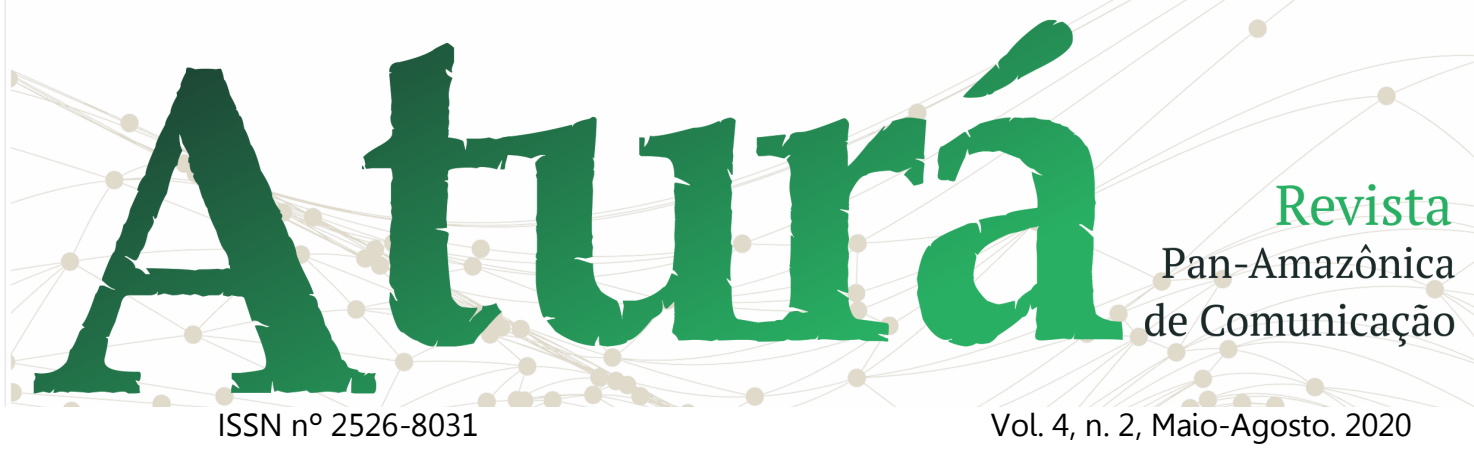

DOI: http://dx.doi.org/10.20873/uft.2526-8031.2020v4n2p150

\title{
A MÁSCARA DO SILÊNCIO: de Anastácia a Kilomba, as mulheres negras romperam a máscara
}

The mask of silence: from Anastácia to Kilomba, black women break the mask.

La máscara del silencio: de Anastácia al Kilomba, mujeres negras rompieron la máscara

\section{Albertina Vieira de Melo Gomes Oliveira, Universidade Federal do Tocantins ${ }^{1}$}

\section{RESUMO}

O presente estudo, apresenta uma breve revisão sobre período da escravatura, do movimento negro feminista e uma análise acerca de como a mulher negra é representada no editorial de gênero do jornal The New York Times, o In Her Words. O objetivo foi apontar como a teoria do matriarcado negro poderia ter atrapalhado ainda mais a mulher negra na luta pelos seus direitos, o movimento feminista negro e entender de que forma o editorial de gênero do jornal The New York Times trabalha a representatividade da mulher negra na mídia. A análise do editorial de gênero apontou que apesar de ter representatividade na mídia, o espaço reservado à mulher negra ainda é reduzido.

PALAVRAS-CHAVE: escravidão; interseccionalidade; mulher negra; escravidão.

\begin{abstract}
This study presents a brief review of the period of slavery, of the black feminist movement and an analysis of how black women are represented in the gender editorial of the New York Times, In Her Words. The objective was to point out how the theory of black matriarchy could have further hampered black women in the fight for their rights, the black feminist movement and to understand how the gender editorial of The New York Times works the representation of black women in media. The analysis of the gender editorial pointed out that despite having representativeness in the media, the space reserved for black women is still reduced.
\end{abstract}

KEYWORDS: slavery; intersectionality; black woman; slavery.

\footnotetext{
1 Bacharel em Jornalismo. Mestranda em Comunicação e Sociedade (UFT). E-mail: albertina.oliveira@mail.uft.edu.br.
} 


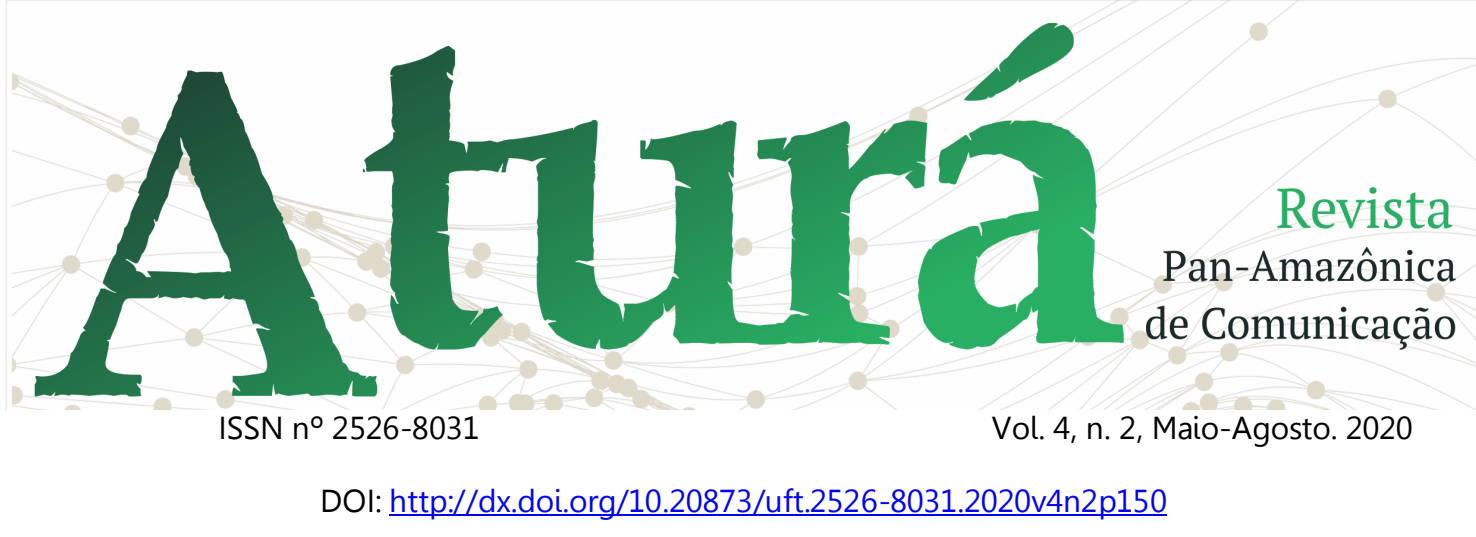

\section{RESUMEN}

Este estudio presenta una breve revisión del período de esclavitud, del movimiento feminista negro y un análisis de cómo las mujeres negras están representadas en la editorial de género del New York Times, In Her Words. El objetivo era señalar cómo la teoría del matriarcado negro podría haber obstaculizado aún más a las mujeres negras en la lucha por sus derechos, el movimiento feminista negro y comprender cómo la editorial de género de The New York Times trabaja la representación de las mujeres negras en medios de comunicación. El análisis del editorial de género señaló que a pesar de tener representatividad en los medios, el espacio reservado para las mujeres negras todavía se reduce.

PALABRAS CLAVE: esclavitud; interseccionalidad; mujer negra; esclavitud.

Recebido em: 12.02.2020. Aceito em: 14.04.2020. Publicado em: 01.05.2020. 


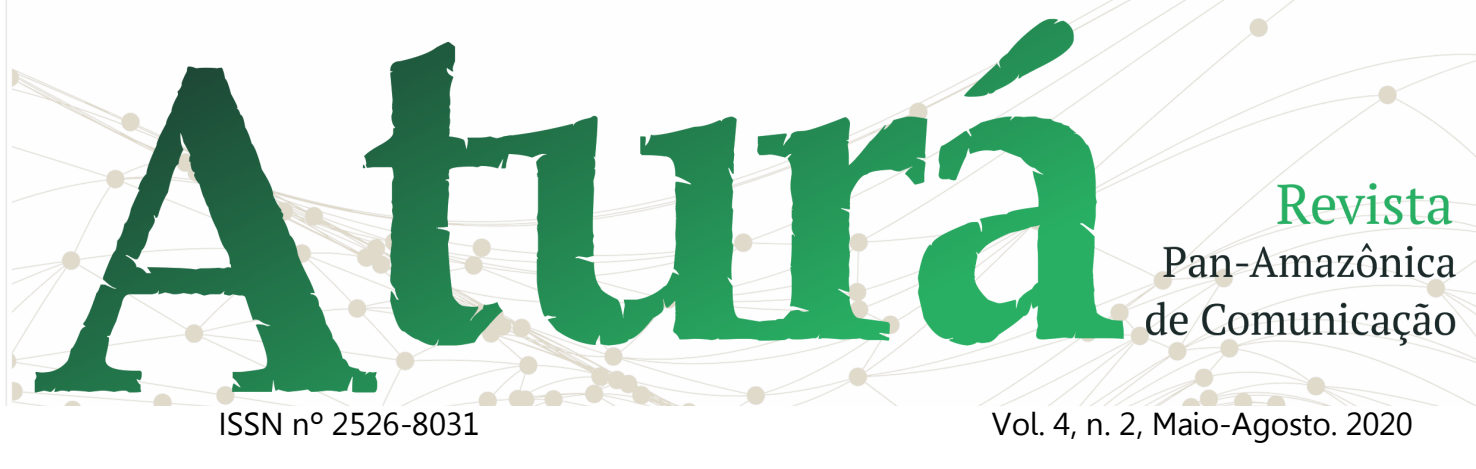

DOI: http://dx.doi.org/10.20873/uft.2526-8031.2020v4n2p150

\section{A escravidão e a teoria do matriarcado} negro.

A reflexão sobre a comunicação na perspectiva de gênero é necessária para avançar rumo a discussão acerca da democratização da comunicação, bem como a representatividade e interseccionalidade nos veículos de comunicação. Nesse sentido o presente artigo tem como objetivo refletir sobre a representatividade da mulher negra nos assuntos abordados na Editoria "In Her Words" do Jornal The New York Times que é um dos jornais mais acessados no mundo. A partir de revisão de literatura e análise de conteúdo dos textos jornalísticos, será discutida a representatividade das mulheres negras na sociedade e consequentemente nos meios de comunicação no qual NYT é parte.

Antes de adentrar ao assunto, é relevante destacar que a autoria do artigo é de uma pesquisadora branca que tem o compromisso de ampliar as discussões entendendo que esse engajamento deve ser acadêmico e político, mas reconhece que não é possível mensurar os racismos sofridos pelas mulheres negras tendo em vista que não é o seu "lugar de fala".

Escrever é um ato de descolonização no
qual se opõe a posições coloniais
tornando-se escritor(a) validada(o),
legitimada(o) e, ao reinventar a si
mesma(o) nomeia uma realidade que fora
nomeada erroneamente ou sequer fora
nomeada. (KILOMBA, 2019 p.28)
O período da escravidão ancora a ancestralidade negra em um misto de colonização, tortura, servidão, racismo, violência sexual e barbárie. Será baseado nisso, o aporte para o entendimento preliminar do movimento feminista negro. $O$ intuito é trazer à tona a teoria do matriarcado ${ }^{2}$ surgida no período da

${ }^{2}$ Foi no estudo de J. J. Bachofen (Das Mutterrecht,1861) que o termo matriarcado foi primeiramente empregado. Um matriarcado é uma sociedade em que alguns, se não todos, os poderes legais relativos à ordenação e governo, do poder da família sobre a propriedade, a herança, sobre o casamento, sobre a casa é alojada às mulheres e não homens. Disponível em: [https://www.tandfonline.com/doi/abs/10.1080 100064246.1970.11430667]. Acesso em 3 jan. 2020. 


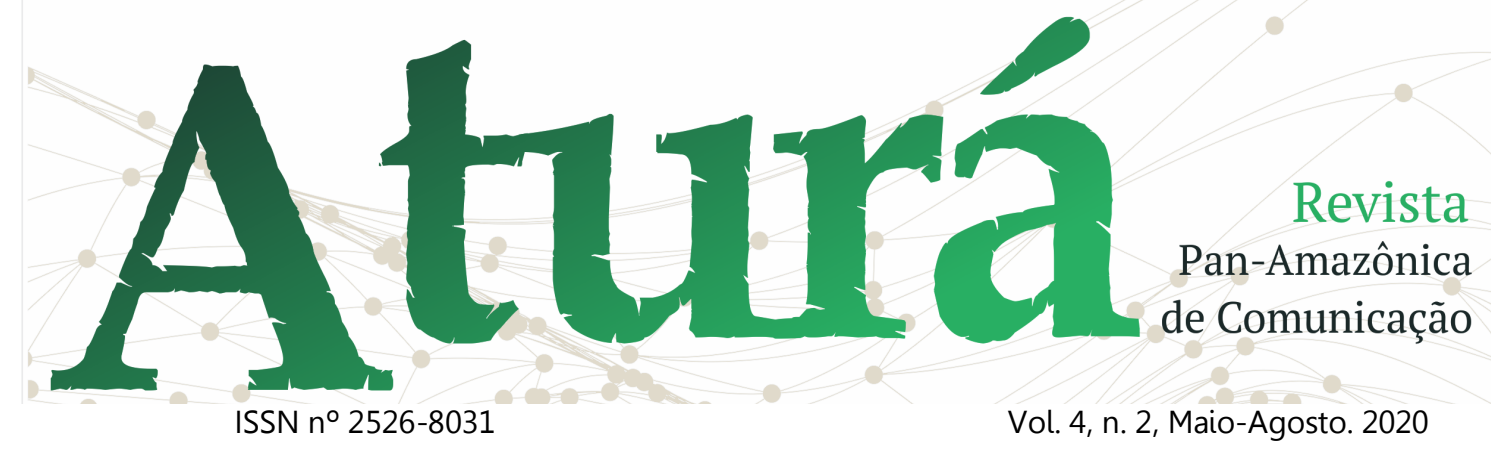

DOI: http://dx.doi.org/10.20873/uft.2526-8031.2020v4n2p150

escravidão ${ }^{3}$ e refutada pelas mulheres negras.

A mulher negra foi tolhida de exercer seus direitos desde a época da escravidão. Seu destino estava entregue ao senhoril, que de acordo com o que fosse conveniente, decidiria de que forma aquela escrava seria útil:

Mas as mulheres também sofriam de forma diferente, porque eram vitimas de abuso sexual e outros maus-tratos bárbaros que só poderiam ser infligidos a elas. A postura dos senhores em relação às escravas era regida pela conveniência: quando era lucrativo explorá-las como se fossem homens, eram vistas como desprovidas de gênero; mas, quando podiam ser exploradas, punidas e reprimidas de modos cabiveis apenas as mulheres, elas eram reduzidas exclusivamente à sua condição de fêmeas. (DAVIS, 2016 p.25)

\footnotetext{
${ }^{3}$ A chamada "escravidão moderna, ou escravidão negra" começou com o tráfico africano no século $\mathrm{XV}$, por iniciativa dos portugueses (em 1444, estes começam a adquirir escravos negros no Sudão), com a exploração da costa da África e a colonização das Américas. Os demais impérios coloniais rapidamente aderiram à prática da compra e venda de seres humanos, no célebre "comércio triangular" entre a África (captura de escravos) a América (venda e troca por matéria prima) e a Europa (para a venda das riquezas obtidas e a retomada do empreendimento, em futuras viagens). Disponível em: [http://www.ufrgs.br/cdrom/depestre/escravidao.ht m] .Acesso em 3 jan. 2020.
}

Tal situação limitava não só a mulher negra, mas o homem negro também, ao status de objeto. A institucionalização de uma espécie de rodízio de abusos, no qual eram impostas as mais variadas formas de barbaridades. A autora afirma ainda que, tão logo iniciou-se a abolição do tráfico internacional de escravos, a capacidade reprodutiva da mulher negra rapidamente foi utilizada como opção para ampliar a população de escravos domésticos, para repor e ampliar a população de escravas e escravos. As escravas passaram a ser avaliadas pela capacidade reprodutiva, pela fertilidade ou pela falta dela.

$$
\text { O sistema escravista promoveu a }
$$
"horizontalidade" de gênero (o senhor tinha que punir o homem negro para manter a cadeia de comando) e (punir a mulher negra para que essa trabalhasse) baseado no medo, que a única hierarquia existente alí era a do senhoril para com os escravos. Na constituição da família negra, não havia supremacia de gênero, ambos eram provedores. (DAVIS, 2016) 


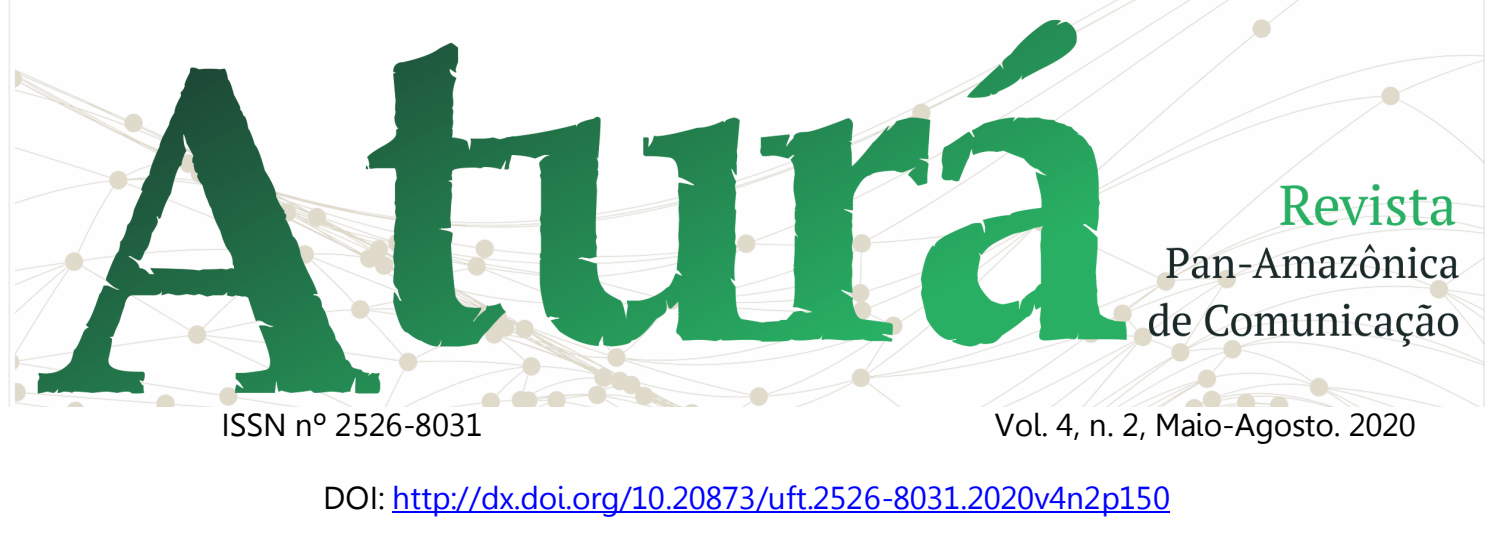

Existem mais abordagens a serem feitas, o assunto é de uma profundidade que permite vários olhares. No entanto, a intenção foi promover aqui o sentimento de que a mulher negra teve negado 0 direito de se enxergar como mulher. Foi coagida a ser o reflexo do homem negro nas obrigações servis, e ainda assim ser reprodutora e escrava sexual.

Hooks (2014) argumenta que no meio acadêmico, teóricos relativizaram o impacto da escravatura nos homens e nas mulheres negras, afirmando que 0 primeiro foi muito mais prejudicado. Alguns historiadores sexistas e sociólogos afirmam que a escravatura foi mais cruel e desumana com o homem negro, que foi despojado de sua masculinidade.

Tão logo a sexualidade do homem negro começou a ser questionada, a masculinidade da mulher negra começou a ser notada. Era comum ver mulheres negras na lavoura, realizando os mesmos afazeres dos homens. Muitas mulheres escravizadas tinham $\circ$ porte físico musculoso, o que foi utilizado como justificativa para masculinizar a figura da mulher negra naquele período. homem branco preocupou-se em como explicar para a sociedade, de que forma a mulher negra conseguia realizar tarefas que: de acordo com a cultura sexista, eram afazeres masculinos. Outra preocupação dos senhores, era a de que tal situação poderia incitar nas mulheres brancas, a vontade de realizar também, os afazeres ditos masculinos.

Para dirimir tal situação, Hooks (2014) cita que as mulheres negras escravas foram taxadas de criaturas subhumanas masculinizadas, que não eram mulheres reais. As mulheres negras estavam ameaçando $\mathrm{o}$ patriarcado instaurado, o poder dos senhores e os homens brancos.

A falta de vontade dos acadêmicos da
atualidade em aceitar como um passo
positivo a igualdade entre os sexos em
qualquer esfera, conduziu à formação da
teoria que a matriarcalidade negra existiu
na estrutura da familia negra. Os cientistas
sociais homens formularam teorias sobre
o poder matriarcal das mulheres negras
para prover uma explicação não ordinária
do papel independente e decisivo da
mulher negra dentro da estrutura da
família negra. (HOOKS, 2014 p.52)

Ainda de acordo com a autora, o termo matriarcal, implica a existência de 


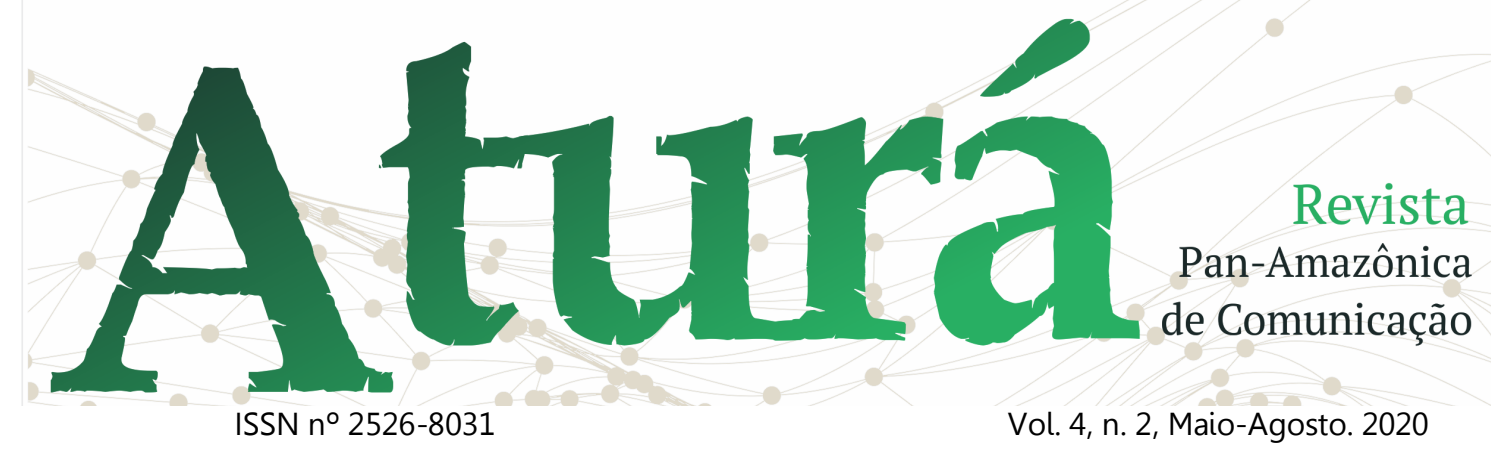

DOI: http://dx.doi.org/10.20873/uft.2526-8031.2020v4n2p150

uma ordem social na qual as mulheres exercem poder político e social, situação nada semelhante a vivida pelas mulheres negras. A ausência de estudos que refutassem as afirmações dos proprietários de escravas, perpetuou uma imagem distorcida da família negra, para que o homem branco pudesse manter sob controle a herança cultural do patriarcado.

Em 4 de junho de 1965, o Presidente Lyndon Johnson discursou na Howard University, muito do que foi dito, teve como aporte o Relatório Moynihan ${ }^{4}$. Escrito por Daniel Patrick Moynihan e Richard Goodwin.

The Negro Family: The Case for National Action, também conhecido como relatório Moynihan apresentava detalhes do que foi o período da escravidão. Nele, os autores trouxeram o aporte de Nathan Glaze em sua pesquisa "Why was American slavery the most awful the world has ever known?" ao traçar um paralelo do que foi a

${ }^{4}$ Disponível em: [https://www.theatlantic.com/polit ics/archive/2015/09/the-moynihan-report-an-ann otated-edition/404632/\#Chapter\%20III]. Acesso em: 3 jan. 2020. escravidão na América do Norte e na América do Sul.

American slavery was profoundly different from, and in its lasting effects on individuals and their children, indescribably worse than, any recorded servitude, ancient or modern. The peculiar nature of American slavery was noted by Alexis de Tocqueville and others, but it was not until 1948 that Frank Tannenbaum, a South American specialist, pointed to the striking differences between Brazilian and American slavery. The feudal, Catholic society of Brazil had a legal and religious tradition which accorded the slave a place as a human being in the hierarchy of society - a luckless, miserable place, to be sure, but a place withal. In contrast, there was nothing in the tradition of English law or Protestant theology which could accommodate to the fact of human bondage - the slaves were therefore reduced to the status of chattels - often, no doubt, well cared for, even privileged chattels, but chattels, nevertheless. Glazer, also focusing on the Brazil-United States comparison, continues. "In Brazil, the slave had many more rights than in the United States: he could legally marry, he could, indeed had to, be baptized and become a member of the Catholic Church, his family could not be broken up for sale, and he had many days on which he could either rest or earn money to buy his freedom. The Government encouraged manumission, and the freedom of infants could often be purchased for a small sum at the baptismal font. In short: the Brazilian slave knew he was a man, and that he differed in degree, not in kind, from his master."13 11 "[In the United States,] the slave was totally removed from the protection of organized society (compare the elaborate provisions for the protection of slaves in the Bible), his 


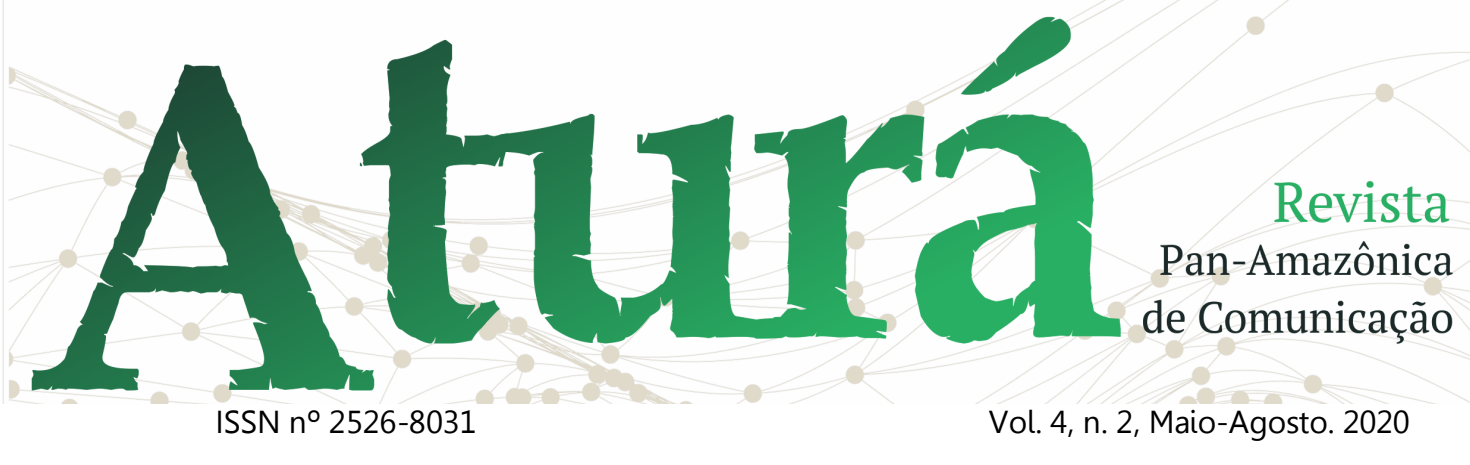

DOI: http://dx.doi.org/10.20873/uft.2526-8031.2020v4n2p150

existence as a human being was given no recognition by any religious or secular agency, he was totally ignorant of and completely cut off from his past, and he was offered absolutely no hope for the future. (MOYNIHAN, 1997 p.10,11)

As raízes de uma escravidão exercida de maneiras diferentes, subtraindo do sujeito a possibilidade, o direito e o dever de exercer quaisquer papéis na sociedade. Nas quais o estudo citado acima, alega que nunca houve uma escravidão tão cruel como a americana.

Tal relatório trazia consigo a herança da teoria do matriarcado negro, oriundo do período da escravidão. Moyniham, afirmava que grande parte dos problemas vividos na América se deviam à estrutura familiar dos negros e ao desajuste que isso causava culturalmente.

The matriarchal pattern of so many Negro families reinforces itself over the generations. This process begins with education. Although the gap appears to be closing at the moment, for a long while, Negro females were better educated than Negro males, and this remains true today for the Negro population as a whole. (MOYNIHAN, 1997 p. 20)

Obras como Slavery, de Stanley Elkins (1959), The Slave Community, de
John Blassingame (1972), The Black Family in Slavery and Freedom, de Herbert Gutman (1976) ascenderam o debate em torno da escravidão e acerca da teoria do matriarcado naquele período. Buscando entender qual era a estrutura familiar da família negra de fato, e permitindo dessa forma uma leitura efetiva do período escravocrata.

$\mathrm{Na}$ contramão, estudiosos como Meacham (1983) citava em sua obra The myth of the black matriarchy under slavery que não era verdadeira a afirmação de que a típica família escrava era matriarcal e que o marido era no máximo assistente de sua esposa.

Quem, entre nós, aguardava com ansiedade uma análise séria sobre as mulheres negras durante o período da escravidão permanece, até o momento, decepcionado. Igualmente decepcionante tem sido a descoberta de que, com exceção do tema tradicionalmente debatido sobre promiscuidade versus casamento e sexo forçado versus sexo voluntário com homens brancos, os autores dessas novas obras têm dado atenção insuficiente às mulheres. O mais esclarecedor de todos esses estudos recentes é a investigação de Herbert Gutman sobre a família negra. Ao trazer evidencias documentais de que a vitalidade da família se mostrou mais forte do que os rigores desumanizantes da escravidão, Gutman destronou a tese 


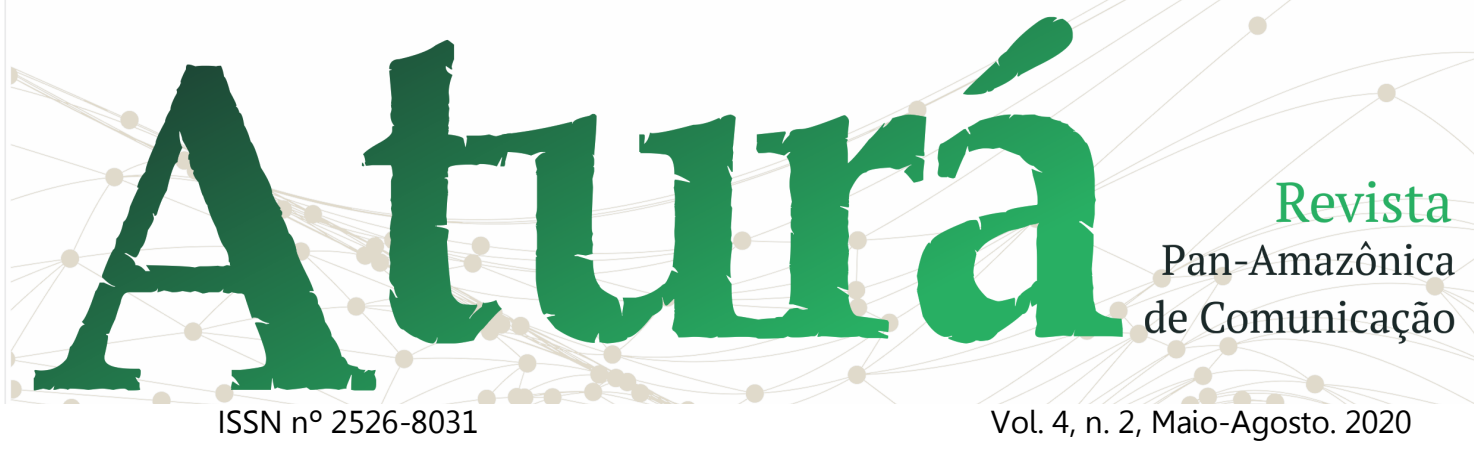

DOI: http://dx.doi.org/10.20873/uft.2526-8031.2020v4n2p150

do matriarcado negro, popularizada em 1965 por Daniel Moynihan e outros. Ainda assim, como as observações que ele faz sobre as mulheres escravas são geralmente elaboradas para confirmar que elas tinham uma propensão a se tornarem esposas, fica fácil extrair disso a implicação de que elas se diferenciavam de suas congeneres brancas apenas na medida em que suas aspirações domésticas eram frustradas pelas exigencias do sistema escravocrata. (DAVIS, 2016 p.24)

Dessa forma, percebe-se que são frustradas as tentativas de incumbir a mulher papéis que não couberam a ela. O matriarcado colocaria a mulher em pé de igualdade ao homem, situação que nunca ocorreu. A teoria do matriarcado negro, tiraria (no sentido de que as mulheres não precisariam mais lutar por nenhum direito ou igualdade, já que eram as provedoras das suas casas e consequentemente chefes de família) das mulheres a oportunidade de lutar por algo que elas nunca tiveram.

\section{A máscara}

Kilomba (2019) cita em sua obra, Memórias da Plantação a máscara da escrava Anastácia ${ }^{5}$ e o grande impacto que aquela imagem causava nos escravizados A máscara do silenciamento, como descreve a autora, era composta por um pedaço de metal colocado no interior da boca da (o) negra (0), entre a língua e o maxilar. Tudo isso, fixado por duas cordas atrás da cabeça, uma em torno do queixo e outra em torno do nariz e da testa.

A imagem abaixo (figura 1) pode causar uma mistura de sentimentos a quem quer que a veja, mesmo que não esteja fisicamente próxima (o). Tome-se daí, a proporção que a utilização da máscara causava sobre os escravos e como a utilização dela serviu para implementar um senso de surdez, dominação, controle e

\footnotetext{
${ }_{5}$ Alguns dizem que Anastácia era filha de uma família real Kimbundo, nascida em Angola, sequestrada e levada para a Bahia e escravizada por uma família portuguesa. Após o retorno dessa família para Portugal, ela teria sido vendida a um dono de uma plantação de cana-de-açúcar. Outros alegam que ela teria sido uma princesa Nagô/Yorubá antes de ter sido capturada por europeus traficantes de pessoas e trazida ao Brasil na condição de escravizada. Enquanto outros ainda contam que a Bahia foi seu local de nascimento. Seu nome africano é desconhecido (KILOMBA, 2019 p. 35)
} 


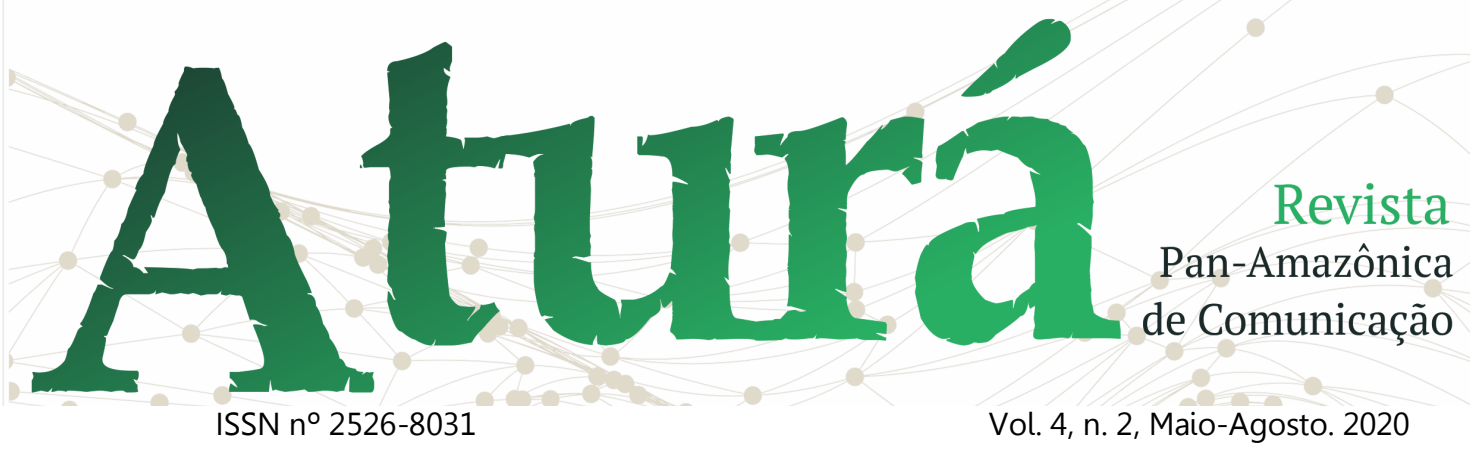

DOI: http://dx.doi.org/10.20873/uft.2526-8031.2020v4n2p150

consequentemente censura. Talvez $\mathrm{o}$ artefato não seja percebido de forma

Figura 1 A máscara do silenciamento física na atualidade, mas pode-se sugerir



que a máscara ainda existe no imaginário social do povo negro.

Fonte: Kilomba - Memórias da Plantação

Do ponto de vista feminista, em muitos contextos em decorrência da intensa desigualdade entre os gêneros, pode-se dizer que a máscara está para Anastácia, assim como o homem está para a mulher, levando-se em consideração Beauvoir (1949), quando esta destacou que o homem mantém com a mulher uma relação de submissão e dominação. Uma vez que, ainda segundo a autora, a mulher não é definida em si mesma, mas sim, em relação ao homem e por meio do olhar dele. Dessa forma, ela é confinada e subjugada a papeis e significações delegados por ele.

Poderia ser a máscara também utilizada aqui como uma metáfora para calar o "outro"? Como calar a voz da mulher negra, senão com a máscara que a calou o povo negro no período da escravidão?

Beauvoir (1949) alegando os ditos acima, afirma que a mulher é o "outro", pensando nessa mulher como um objeto, algo que tem serventia por um momento. Ribeiro (2019) afirma que de modo geral, a mulher é o eco da figura masculina, é a imagem que o homem vê de si mesmo no espelho, ignorando o fato desse "outro" não ser um homem, e afirma ainda, que a mulher negra é o outro do outro (a mulher branca), porquanto sempre foi invisibilizada pela sociedade. 


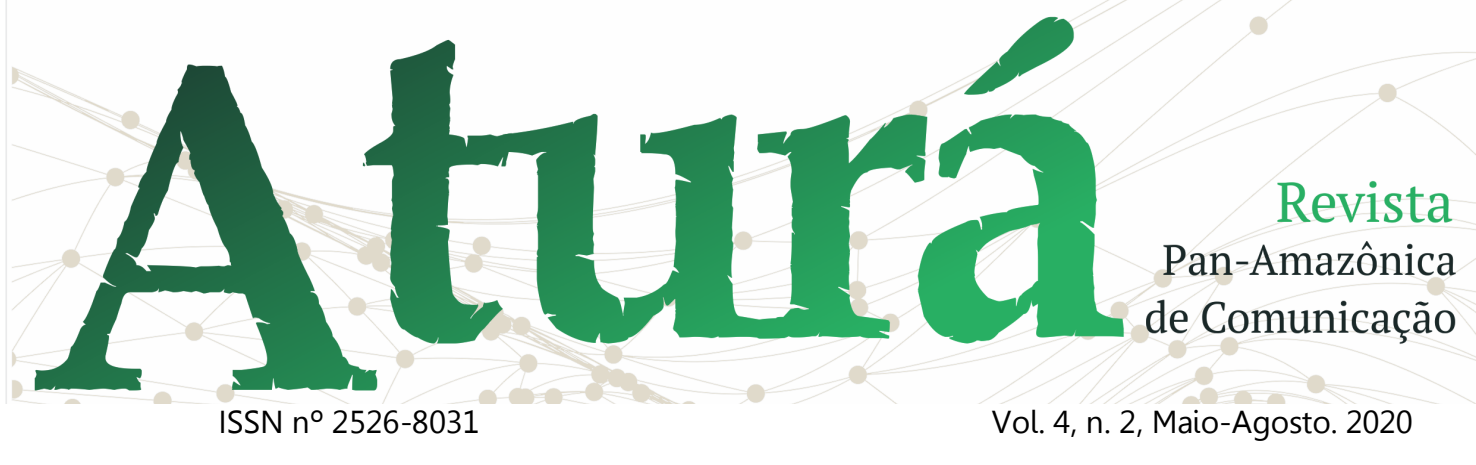

DOI: http://dx.doi.org/10.20873/uft.2526-8031.2020v4n2p150

O racismo, o desconhecimento e a falta de interesse em conhecer a história do outro também podem ser consideradas formas de calar, de instaurar um senso de surdez e de dominar.

Diante disso, a importância em discutir e revisar historicamente a importância do movimento feminista negro para a representatividade da mulher negra na sociedade. Por meio da interseccionalidade, o feminismo negro abriu espaço para as mulheres negras, que antes eram a minoria dentro de um movimento feminista hegemônico, liderado por mulheres brancas.

\section{O movimento feminista negro.}

O feminismo negro nasceu de descontentamentos, da falta de representatividade, de oportunidade e de direitos sociais. Apesar de as mulheres negras entenderem que os direitos das mulheres eram importantes e pungentes, as necessidades das mulheres brancas e das mulheres negras eram diferentes.

Davis (2016) afirma que a revolução industrial promoveu uma mudança na base da sociedade estadunidense. A vida das mulheres brancas mudou, pois por volta dos anos 1830 o sistema fabril absorveu as atividades econômicas antes desenvolvidas pelas mulheres. Dessa forma, esse processo desestabilizou a percepção do papel da mulher e do caráter produtivo dela no ambiente doméstico.

$\mathrm{Na}$ verdade, o lugar da mulher sempre tinha sido em casa, mas durante a era préindustrial a própria economia centrava-se na casa e nas terras cultiváveis ao seu redor. Enquanto os homens lavravam o solo (frequentemente com a ajuda da esposa), as mulheres eram manufatoras, fazendo tecidos, roupas, velas, sabão e praticamente tudo o que era necessário para a família. O lugar das mulheres era mesmo em casa - mas não apenas porque elas pariam e criavam as crianças ou porque atendiam às necessidades do marido. Elas eram trabalhadoras produtivas no contexto da economia doméstica, e seu trabalho não era menos respeitado do que 0 de seus companheiros. Quando a produção manufatureira se transferiu da casa para a fábrica, a ideologia da feminilidade começou a forjar a esposa e a mãe como modelos ideais. No papel de trabalhadoras, ao menos as mulheres gozavam de igualdade econômica, mas como esposas eram destinadas a se tornar apêndices de seus companheiros, serviçais de seus maridos. No papel de mães, eram definidas como instrumentos passivos para a reposição da vida humana. A situação da dona de casa branca era cheia 


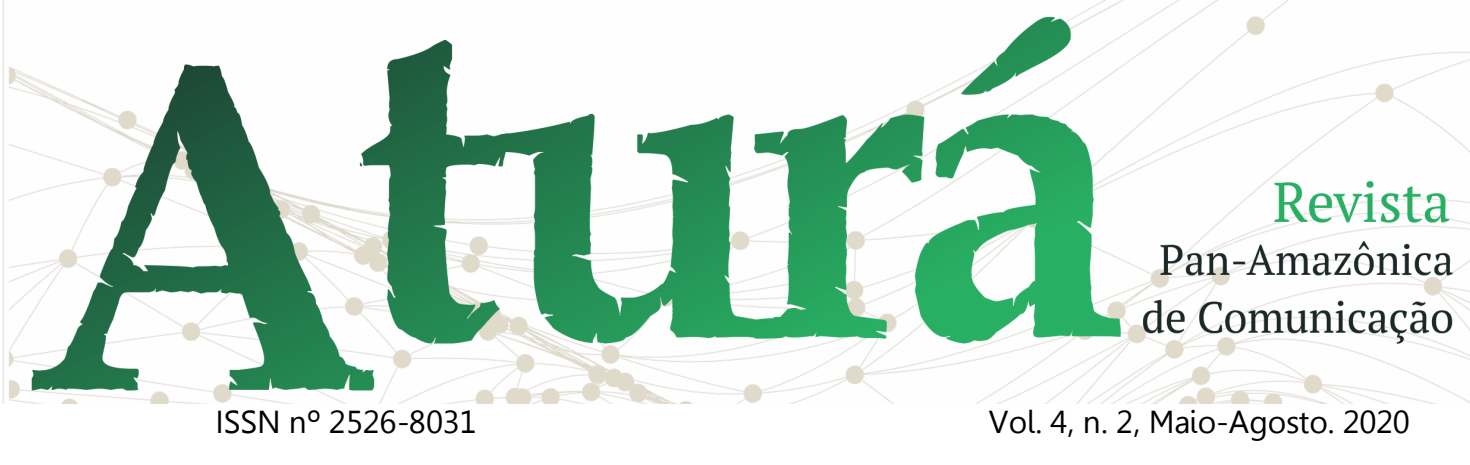

DOI: http://dx.doi.org/10.20873/uft.2526-8031.2020v4n2p150

de contradições. Era inevitável que houvesse resistencia. (DAVIS, 2016 p.50)

A autora reitera ainda, que as donas de casa brancas de classe média, frequentemente evocavam a metáfora da escravidão ao denunciarem a insatisfação de suas vidas domésticas, alegando que a instituição do matrimônio as relegava a uma forma de prisão e servidão.

O que para as mulheres brancas soava como castração de direitos, era uma realidade há muito conhecida pela mulher negra, que desde o período da escravidão, teve a mão de obra explorada. As mulheres negras então iniciam um movimento feminista com aspirações e reinvindicações direcionadas também para mulheres de outras etnias, beneficiando as asiáticas, mexicanas, hispânicas e as demais mulheres do chamado terceiro mundo. Enquanto as feministas brancas norte-americanas baseavam as suas reinvindicações em um feminismo feito por mulheres brancas de classe média alta, casadas, com filhos. (REYES, LAGUARDIA, 2013)

Entre os dias 19 e 20 de julho de 1848, em Seneca Falls- NY aconteceu a primeira Convenção de Seneca Falls ${ }^{6}$, anunciada também como a primeira convenção dos direitos das mulheres dos Estados Unidos da América. A reunião deu início ao movimento do sufrágio feminino, que culminou posteriormente no direito ao voto feminino.

Após dois anos da realização da convenção em Seneca Falls, a cidade de Worcester no estado de Massachusetts sediava a primeira Convenção Nacional pelos Direitos das Mulheres, ocasião na qual Sojourner Truth $^{7}$ proferiu seu discurso: Não sou eu uma mulher ${ }^{8}$ ? No qual alegava ter as mesmas capacidades de trabalho de um homem e requeria os direitos civis das mulheres.

\begin{abstract}
O feminismo negro começou a ganhar força a partir da segunda onda do feminismo, entre 1960 e 1980, por conta da fundação da National Black Feminist, nos Estados Unidos, em 1973, e porque feministas negras passaram a escrever sobre o tema, criando uma literatura
\end{abstract}

\footnotetext{
${ }^{6}$ Disponível em <https://www.loc.gov/item/todayin-history/july-19/>. Acesso em: jan de 2020.

7 Biografia disponível em: <https://www.biograph y.com/news/sojourner-truth-black-history $\geq$. Acesso em: 15 jan. 2020.

${ }^{8}$ Disponível em:

$<$ https://www.nps.gov/articles/sojoUrnertruth.htm>, e <https://www.thesojournertru thproject.com/compare-the-speeches/ $\geq$. Acesso em: 15 jan. 2020.
} 


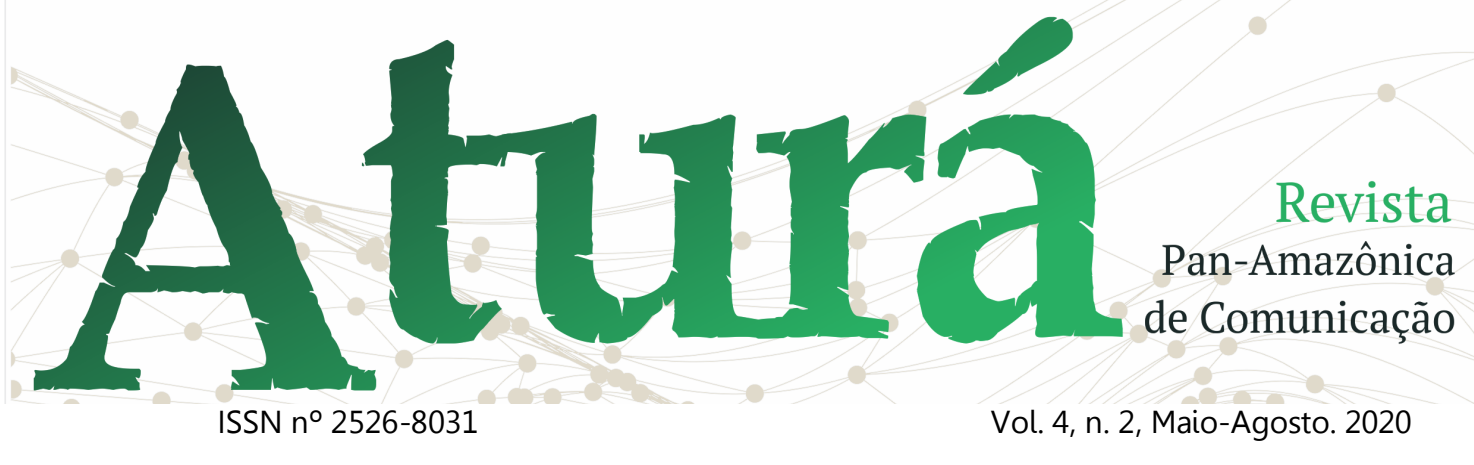

DOI: http://dx.doi.org/10.20873/uft.2526-8031.2020v4n2p150

feminista negra. Porém, gosto de dizer que, bem antes disso, mulheres negras já desafiavam o sujeito mulher determinado pelo feminismo. (RIBEIRO, 2018 p.148)

Ribeiro reacende em sua obra Quem tem medo do feminismo negro (2018), a discussão sobre a máscara do silêncio, citada anteriormente, e trata da utilização do artefato na implementação da cultura do silêncio e do senso de surdez no período colonial. Contrapondose a isso, ao começar a expressar suas ideias e ideais, o movimento feminista negro, rompe a máscara e se coloca não mais como objeto (a ser definido pelo seu colonizador), mas sim como um sujeito (responsável pelos seus atos).

As mulheres negras, ao decidirem apoiar o movimento feminista liderado pelas mulheres brancas, estavam de certa forma "aos olhos dos homens negros" deixando de apoiar o movimento abolicionista negro em busca de igualdade dos direitos civis. No entanto, a mulher negra precisava optar entre ficar sob o patriarcado do homem negro ou lutar junto com a mulher branca, com o intuito de se fazer reconhecer. Pode-se aplicar ao fato descrito acima, o conceito de sororidade ${ }^{9}$, cunhado originalmente nos anos 70 pela escritora norteamericana Kate Millett, o termo sisterhood refere-se a irmandade.

Hooks em sua obra $O$ feminismo é para todo mundo (2018), reitera que ao se agruparem e promoverem em conjunto um movimento potente, as mulheres abriram mão de fazer uso de poder de classe e raça para dominar outras mulheres, porquanto em situação diferente a sororidade não se estabeleceria.

Essa base se apoiou em nossa crítica do que então chamávamos de "o inimigo interno", em referência ao nosso sexismo internalizado. Sabíamos, por experiência própria, que, como mulheres, fomos socializadas pelo pensamento patriarcal para enxergar a nós mesmas como pessoas inferiores aos homens, para nos ver, sempre e somente, competindo umas com as outras pela aprovação patriarcal, para olhar umas às outras com inveja, medo e ódio. O pensamento sexista nos fez julgar sem compaixão e punir duramente umas às outras. O pensamento feminista nos ajudou a desaprender o auto-ódio feminino. Ele nos permitiu que nos libertássemos do controle do pensamento patriarcal sobre nossa consciência. A ligação entre homens era

\footnotetext{
${ }^{9}$ Disponível em: <https://brasil.elpais.com/brasil/2 017/07/10/cultura/1499708850_128936.html>. Acesso em: 18 jan. 2020.
} 


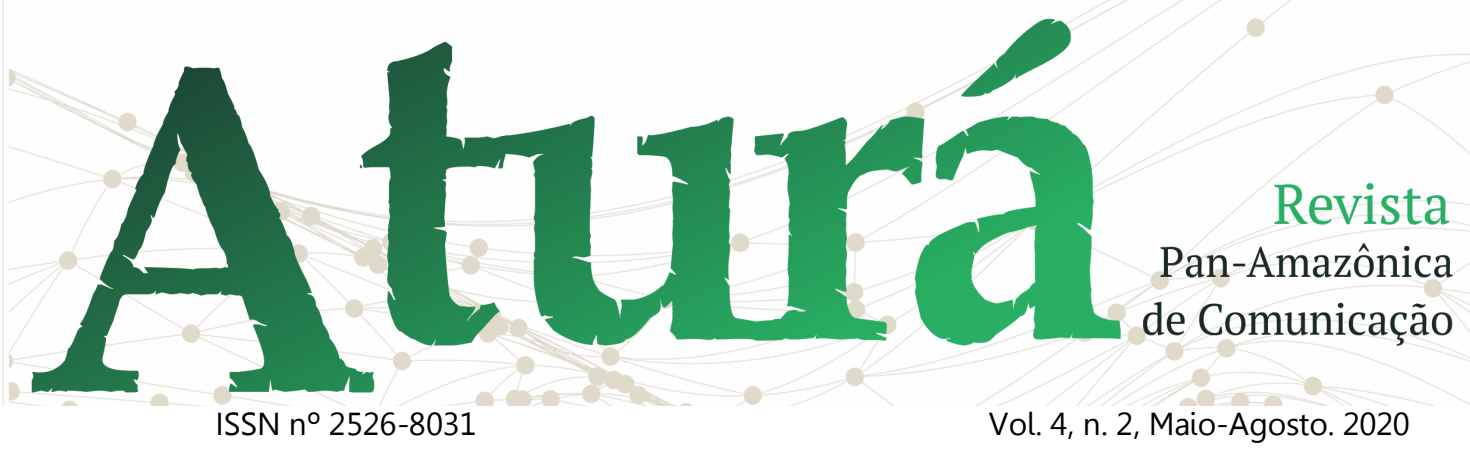

DOI: http://dx.doi.org/10.20873/uft.2526-8031.2020v4n2p150

um aspecto aceito e afirmado na cultura patriarcal. Simplesmente pressupunha-se que homens em grupos ficariam unidos, dariam apoio uns aos outros, seriam um time e colocariam o bem do grupo acima de ganhos e reconhecimento individuais. A ligação entre mulheres não era possivel dentro do patriarcado; era um ato de traição. Movimentos feministas criaram o contexto para mulheres se conectarem. Não nos juntamos para ficar contra os homens; juntamo-nos para proteger nossos interesses de mulher. Quando desafiávamos professores que não adotavam livros escritos por mulheres, não era porque não gostávamos daqueles professores (muitas vezes gostávamos); com razão, queríamos o fim dos preconceitos de gênero em sala de aula e no currículo. (HOOKS, 2018 p.28)

A partir do momento que as mulheres negras encontraram representatividade em movimentos hegemônicos, foi possível lutar de forma ativa contra o sexismo. Enquanto as mulheres brancas buscavam a equiparação dos direitos civis aos dos homens, as mulheres negras buscavam uma forma de sair da invisibilidade.

A situação exposta acima, ilustra bem o conceito de interseccionalidade. A mulher negra encontrou seu lugar de fala, sendo minoria, onde se podia sentir representatividade.
O termo interseccionalidade foi elaborado por Kimberlé Crenshaw10, com o objetivo de nominar e sistematizar a epistemologia das ativistas e intelectuais negras interessadas em discutir questões de raça, gênero, classe, sexualidade e dentre outros da mesma natureza que não atuam de forma isolada, mas se sobrepõem e se combinam, dando maior complexidade para as estruturas de poder e subalternidade. (CORRÊA, LAURA GUIMARÃES et al 2018).

Tais organizações, ainda segundo as autoras, atribuem e definem significados e signos às falas dos sujeitos, revestindo-as de (des)legitimidade discursiva, de acordo com o local ocupado na sociedade.

Quando Crenshaw cunhou o termo interseccionalidade, permitiu uma linearidade no discurso, no sentido de aquiescer a sociedade a dialogar de forma natural, sem conflitos sociais, de raça e gênero. Dessa forma, o movimento negro feminista e os demais movimentos

\footnotetext{
${ }^{10}$ Biografia disponível em : <https://law.ucla.edu/fa culty/faculty-profiles/kimberle-w-crenshaw/>.

Acesso em: 18 jan. 2020.
} 


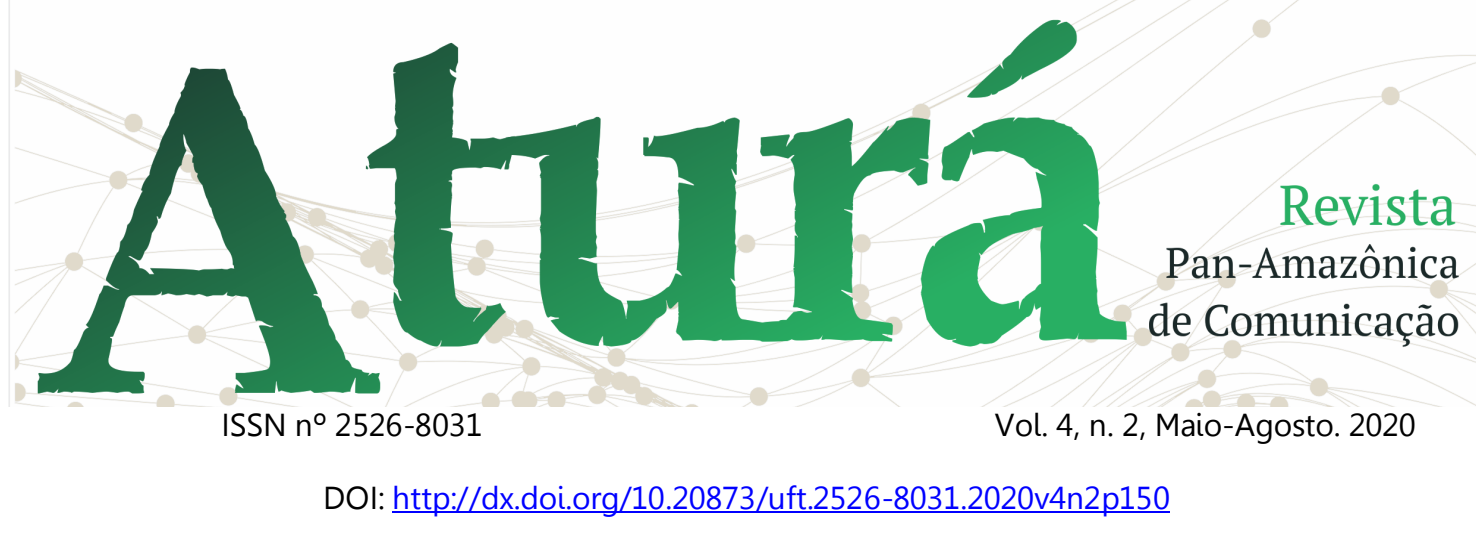

que eram minoria dentro de uma maioria hegemônica, tem voz e representatividade ao discursar.

A seguir, será apresentada uma análise realizada em textos jornalísticos no editorial de gênero do jornal The New York Times - In Her Words - no sentido de contextualizar como a mulher negra é representada naquele espaço.

\section{A mulher negra na editoria "in her} words ${ }^{11 "}$ do jornal the new york times.

A presente pesquisa busca oferecer subsídios para entender a importância da comunicação na perspectiva de gênero focando especialmente na questão da interseccionalidade no material jornalístico produzido pela Editoria "In Her Words" do Jornal The New York Times para verificar se há representatividade da mulher negra nesse espaço jornalístico.

Para isso, foi utilizado como corpus 68 textos jornalísticos da editoria de gênero do jornal The New York Times, selecionados dentro do recorte temporal

${ }^{11}$ Editoria de gênero criada pelo jornal americano The New York Times, com o intuito de promover uma comunicação na perspectiva de gênero. Teve a primeira publicação em abril de 2018. de 28 de abril de 2018 a 28 de abril de 2019. Para realização da pesquisa textual, a palavra black foi definida como chave para a busca nos textos. Foi utilizado como campo de busca o corpo principal do texto. A partir daí, avaliou-se a semântica e a relevância da palavra dentro do contexto do fato exposto no texto.

Foram encontrados 14 textos jornalísticos que contemplavam o critério selecionado acima. Após a seleção foi realizada a leitura dos textos selecionados, o que serviu de arcabouço para as impressões que serão descritas abaixo. No quadro a seguir, serão relacionados os textos selecionados e as datas nas quais foram publicados 


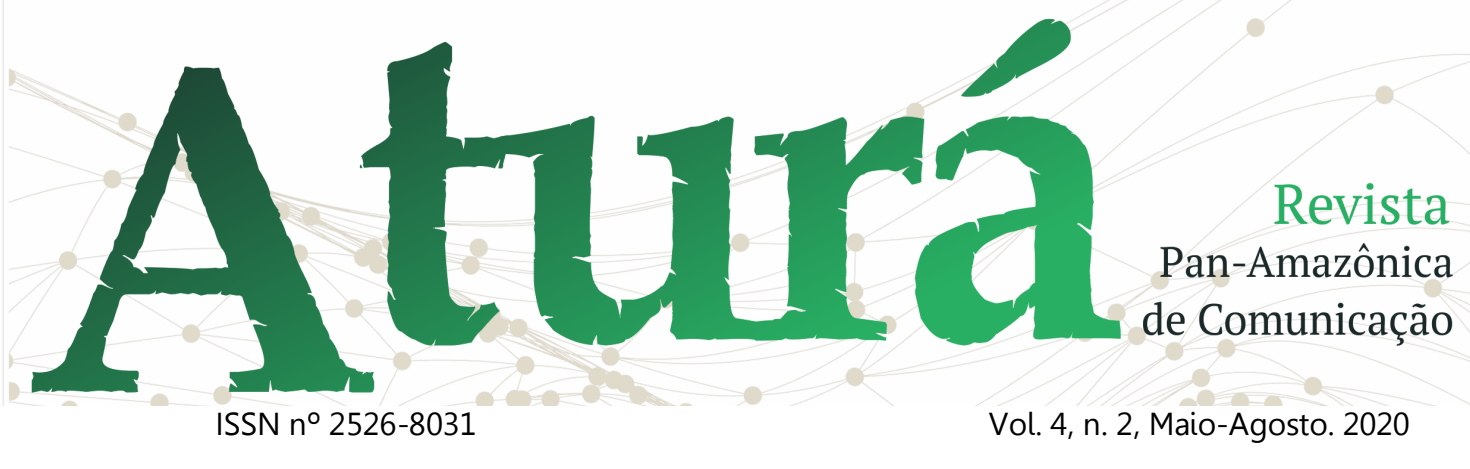

DOI: http://dx.doi.org/10.20873/uft.2526-8031.2020v4n2p150

Tabela 1: Relação de textos jornalísticos analisados

\begin{tabular}{|l|l|}
\hline Título & Data de publicação \\
\hline Moms, They Get the Job Done & $20 / 04 / 2018$ \\
\hline Remembering New York City's First Female Cab Driver & $04 / 05 / 2018$ \\
\hline Meghan Markle, Our Anti-Princess Princess, Builds a Bridge & $18 / 05 / 2018$ \\
\hline Stop Being Grateful! Graduation Advice from 12 Women. & $31 / 05 / 2018$ \\
\hline Hollywood Is as White, Straight and Male as Ever & $02 / 08 / 2018$ \\
\hline $\begin{array}{l}\text { When the Resistance Meets the Polls: A Historic Week for } \\
\text { Women Politicians }\end{array}$ & $16 / 08 / 2018$ \\
\hline $\begin{array}{l}\text { Serena's Not Alone. Women Are Penalized for Anger at Work, } \\
\text { Especially Black Women. }\end{array}$ & $13 / 09 / 2018$ \\
\hline $\begin{array}{l}\text { Christine Blasey Ford Pushes Back: Here's What Might Happen } \\
\text { Next }\end{array}$ & $21 / 09 / 2018$ \\
\hline $\begin{array}{l}\text { They Challenged the Status Quo. On Tuesday, They'll Find Out } \\
\text { Who's With Them. }\end{array}$ & $02 / 11 / 2018$ \\
\hline 2018: Year of the Woman, in 5 Powerful Quotes & $28 / 12 / 2018$ \\
\hline R. Kelly: Why So Many Ignored the Warning Signs & $11 / 01 / 2019$ \\
\hline Taking Back 'Hysterical' & $26 / 02 / 2019$ \\
\hline Traveling the World, While Looking Over Her Shoulder & $26 / 03 / 2019$ \\
\hline Why Music Festivals Need More Beyoncés & $26 / 04 / 2019$ \\
\hline
\end{tabular}

Fonte: elaborado pela autora.

Após a seleção dos textos, foi feita a leitura mais aprofundada, a fim de trazer para a análise uma reflexão de como a In Her Words deu voz a mulher negra dentro do recorte temporal selecionado para esta pesquisa.
No texto Moms, They Get the Job Done, publicado em 20 de abril de 2018 traz a tona a importância da valorização do trabalho da mulher dentro da dicotomia público-privada, uma vez que lidar com os contratempos da casa e chegar a tempo para realizar as tarefas do 


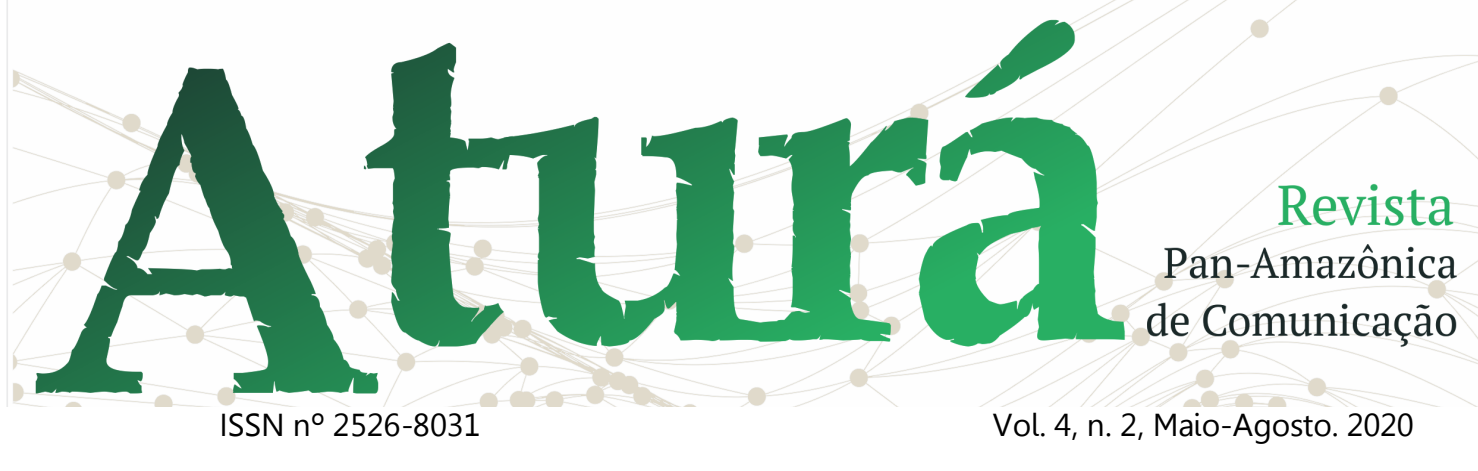

DOI: http://dx.doi.org/10.20873/uft.2526-8031.2020v4n2p150

trabalho não é algo que seja presente na realidade de todos os homens. Aborda ainda a porcentagem (44\%) de mulheres que tem menos chance de conseguir uma recolocação profissional após a maternidade.

That "motherhood penalty," as it is known, is worse for women of color, who are more likely to be the breadwinners in their homes. (This is an absolutely crucial piece of journalism on black mothers and infant mortality I'll come back to in a moment.) It exists despite research showing that moms are actually more productive and ambitious than women without children (no time for nonsense, right?). (BENNETT, 2018a, In Her Words, p. sn)

Tal situação é conhecida como a penalidade da maternidade, e é pior ainda para as mulheres de cor, que são mais propensas a serem provedoras de seus lares. $O$ texto expõe a importância de discutir de como situações semelhantes acometem as mulheres de formas diferentes. A importância da interseccionalidade aplicada aos vários tipos de situações, nas quais geralmente o conceito de classe, raça e gênero não seriam explorados.

Em Remembering New York City's First Female Cab Driver, texto publicado em 4 de maio de 2018 relembra a importância e os desafios encontrados por Gertrude Jeannette, primeira motorista de taxi mulher da cidade de New York nos anos 1940.

To find a female taxi driver in New York City remains rare, so to imagine this woman doing her thing at a time when black drivers like her often endured racist insults - and were bullied into working in particular parts of the city - is remarkable. (BENNETT, 2018b, In Her Words, p. sn)

A autora afirma que muitos gritavam: - uma motorista de taxi, uma motorista de taxi! Estarrecidos com o fato de uma mulher, acima de tudo negra, estar ocupando um posto de trabalho que culturalmente estava definido para os homens.

No dia 18 de maio de 2018 a In Her Words publicou o texto Meghan Markle, Our Anti-Princess Princess, Builds a Bridge, no qual anunciava a então princesa Megan Markle como a antiprincesa. Falava da importância da representatividade da imagem de uma princesa negra na vida real, para milhões de mulheres no mundo acostumadas ao padrão Disney de princesas brancas. 




DOI: http://dx.doi.org/10.20873/uft.2526-8031.2020v4n2p150

Flip through a stack of fairy tales and try to find a heroine like Ms. Markle: a 36year-old biracial actress and philanthropist; a child of divorce who is herself divorced, with strained sibling ties; a self-described feminist who spoke about gender equality at the United Nations Women's conference in 2015. She has lived an adult life outside of Prince Harry's orbit; they only met two years ago. (SALAM, 2018a, In Her Words, p. sn)

Ainda em relação as princesas da Disney e o fato de a primeira princesa negra dos desenhos da Disney, Tiana ( $A$ princesa e o Sapo, 200912) ter tudo uma trajetória atípica em relação aos demais filmes do mesmo segmento da empresa. Pode-se traçar um paralelo entre a trajetória de Markle ${ }^{13}$ e Tiana, não começa como uma princesa, mas como uma jovem que sonha em ter o seu próprio restaurante pois acredita que somente pelo trabalho ela será capaz de chegar ao sucesso. São histórias de luta e de sucesso de meninas negras.

\section{Stop Being Grateful! Graduation}

Advice from 12 Women. Esse é o título do texto publicado pela In Her Words no dia

\footnotetext{
12 Disponível em: <https://www.imdb.com/title/tt07 80521/>. Acesso em: 20 jan. 2020.

${ }^{13}$ Biografia disponível em: <https://www.biograph y.com/royalty/meghan-markle>. Acesso em: 20 jan. 2020.
}

31 de maio de 2018 no qual sugere que as mulheres deveriam repensar no motivo pelo qual se sentem grata pelas coisas, enquanto os homens sentem que justamente as mereciam. Oferece reflexões de mulheres em discursos feitos em grandes universidades dos Estados Unidos, fato que aconteceu pela primeira vez em pelo menos duas décadas.

Para isso, o texto reuniu doze discursos de grandes mulheres, nos quais elas ofereciam conselhos para as outras mulheres que as assistiam. Dentre as doze mulheres, estavam 4 mulheres negras que fizeram discursos de grande impacto em conceituadas universidades dos Estados Unidos:

- Anita Hill14 - Escola de Direito de Rutgers no ano de 2018

- Oprah Winfrey ${ }^{15}$ - Universidade do Sul da Califórnia no ano de 2018

\footnotetext{
${ }^{14}$ Disponível em: [https://abcnews.go.com/US/ani ta-hill-tells-law-school-graduates-metoomovement/story?id=55230148]. Acesso em: 20 jan. 2020.

15 Disponível em: [http://www.oprah.com/owndigitaloriginals/oprahs-inspirationalcommencement-speech-at-usc]. Acesso em: 20 jan. 2020.
} 


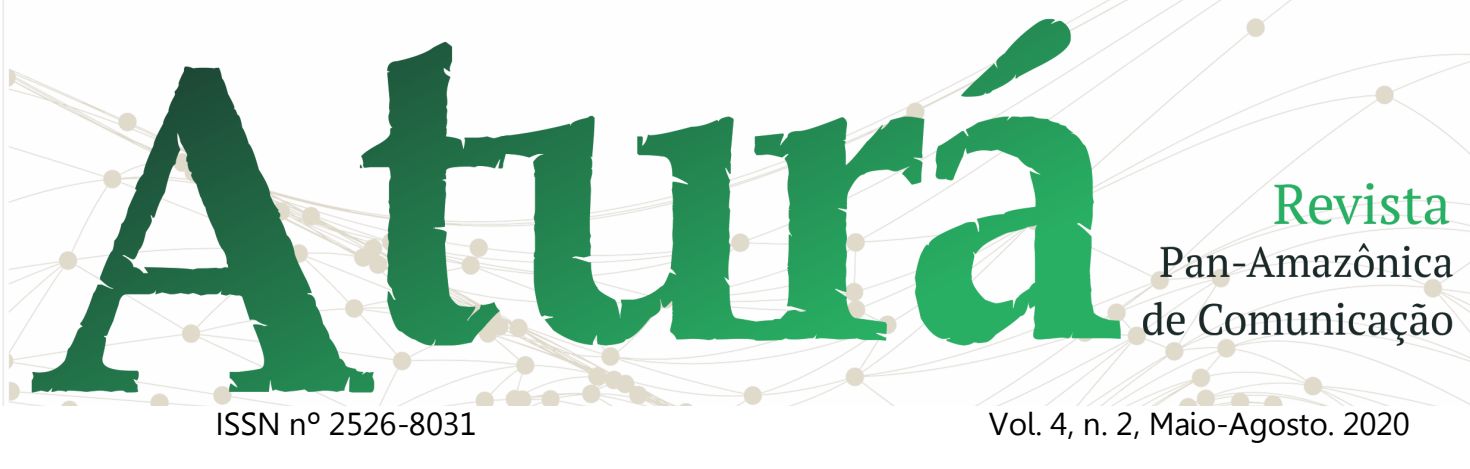

DOI: http://dx.doi.org/10.20873/uft.2526-8031.2020v4n2p150

- Shonda Rhimes ${ }^{16}$ - Faculdade de Dathmouth no ano de 2014

- Michelle Obama ${ }^{17}$ - Faculdade Spellmam no ano de 2011

Quando publicou Hollywood Is as White, Straight and Male as Ever em 2 de agosto de 2018, a In Her Words falou acerca das denúncias de assédio sexual na indústria cinematográfica e comemorou o aumento dos filmes com pessoas negras e com diferentes padrões do que vinha sendo praticado pela indústria Hollywoodiana. Fimes como: Pantera Negra, Mulher Maravilha, Call me by your name e também repercussão da hashtag \#oscarsowhite18, um protesto pedindo mais diversidade na premiação e a respeito da quantidade de atores

16 Disponível em: [http://www.dartmouth.edu/commence/news/spee ches/2014/rhimes-address.html]. Acesso em: 22 jan. 2020.

17 Disponível em: [https://obamawhitehouse.archives.gov/the-pressoffice/2011/05/15/remarks-first-lady-spelmancollege-commencement] . Acesso em: 22 jan. 2020.

${ }^{18}$ Disponível em:<https://www.bbc.com/portuguese /noticias/2016/01/160122_oscar_academia_divers idade_rm>. Acesso em jan. de 2020. negros $^{19}$ que já haviam recebido um Oscar.

Salam (2018b) Traz a memória da primeira pessoa negra a receber um Oscar, a atriz Hattie MacDaniel no ano de 1940 por seu papel como "mamãe" no filme E o vento levou (1939). Durante a premiação, MacDaniel não estava sentada junto aos demais convidados, e sim em uma mesa contra a parede, pois o hotel onde os prêmios foram entregues tinha uma política de não-negros.

When the Resistance Meets the Polls: A Historic Week for Women Politicians, foi o título do texto publicado em 16 de agosto de 2018, Salam (2018c) falou a respeito do número recorde de mulheres e LGBTQIA+ assumindo cargos políticos. Falava também respeito da possível eleição de Stacey Abrams na Geórgia, que viria a ser o primeiro Estado a eleger uma mulher negra como governadora.

Serena's Not Alone. Women Are Penalized for Anger at Work, Especially

${ }^{19}$ Apenas 44 negros já receberam o Oscar até hoje. Disponível em: <http://www.adorocinema.com/noticias/filmes/noti cia-151831/>. Acesso em :22 jan. 2020. 


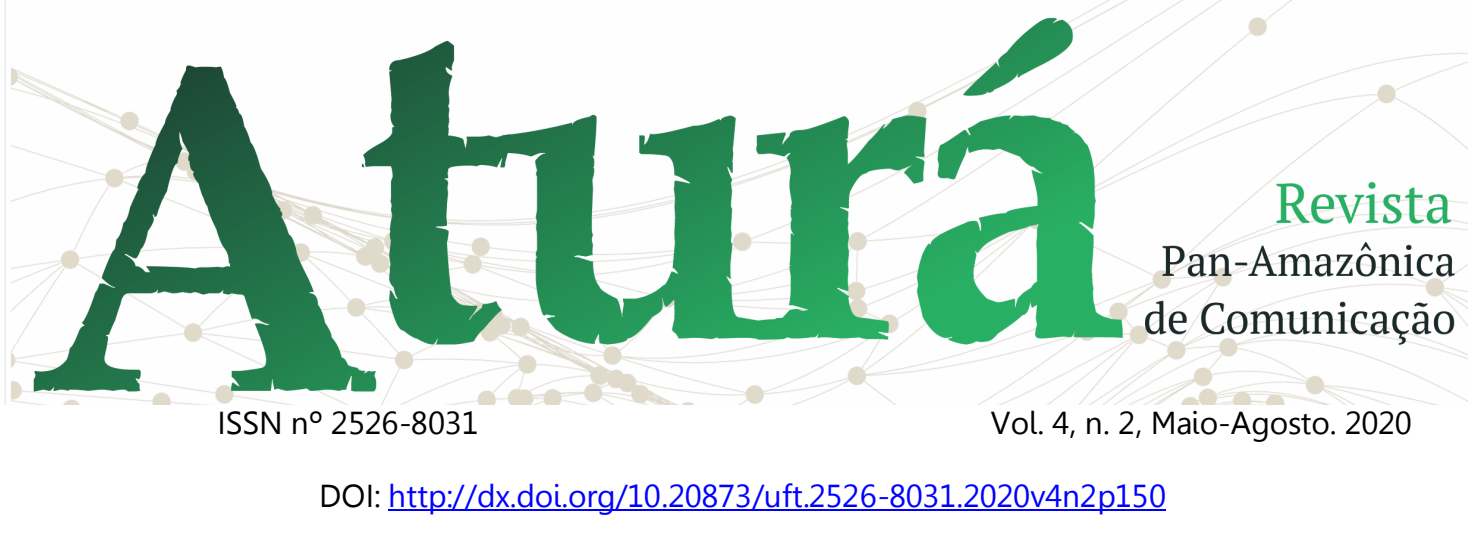

Black Women foi publicado no dia 13 de setembro de 2018 e falava a respeito de como homens e mulheres são penalizados de forma diferente, por externarem raiva no ambiente de trabalho. Para isso, trouxe como exemplo o episódio com a tenista Serena Willians, que durante o US Open se irritou com o árbitro, chamou-o de mentiroso, ladrão e quebrou sua raquete arremessando-a ao chão. O episódio custou a Willians o jogo em questão.

Salam (2018d) traça um paralelo do ocorrido com Willians ao citar a reportagem de Jason Hahn The Biggest Male On-Court Meltdowns in Tennis History ${ }^{20}$, no qual falava sobre episódios semelhantes protagonizados por homens, onde foi possível perceber a diferença de tratamento dada a Willians e a proporção que o caso tomou.

Christine Blasey Ford Pushes Back: Here's What Might Happen Next foi o texto publicado no dia 21 de setembro de 2018 e trazia semelhanças entre as

${ }^{20}$ Disponível em: <https://people.com/sports/maleon-court-meltdowns-tennis-history/ $\geq$. Acesso em: 22 jan. 2020. denúncias de assédio sexual feitas por Anita Hill contra o juiz Clarence Thomaz há aproximadamente 29 anos e a denúncia feita por Christine Blasey Ford contra o juiz Brett Kavanaugh no ano de 2018.

Salam (2018e) versa sobre a importância do apoio das mulheres negras ao discurso de Anita Hill, na época da acusação contra Thomaz. No ano de 1991 muitas mulheres negras adicionaram seus nomes a um anúncio de página inteira no The New York Times, protestando contra a confirmação de Clarence Thomaz para a suprema corte dos Estados Unidos.

Salam (2018) no texto They Challenged the Status Quo. On Tuesday, They'll Find Out Who's With Them, publicado em 2 de novembro de 2018 falava a respeito do resultado das eleições nos Estados Unidos da América. Das 964 vagas abertas para cargos eleitorais no país, 272 delas foram ocupadas por mulheres, sendo 215 delas mulheres de cor e 26 pertencentes ao movimento LGBTQI+. 


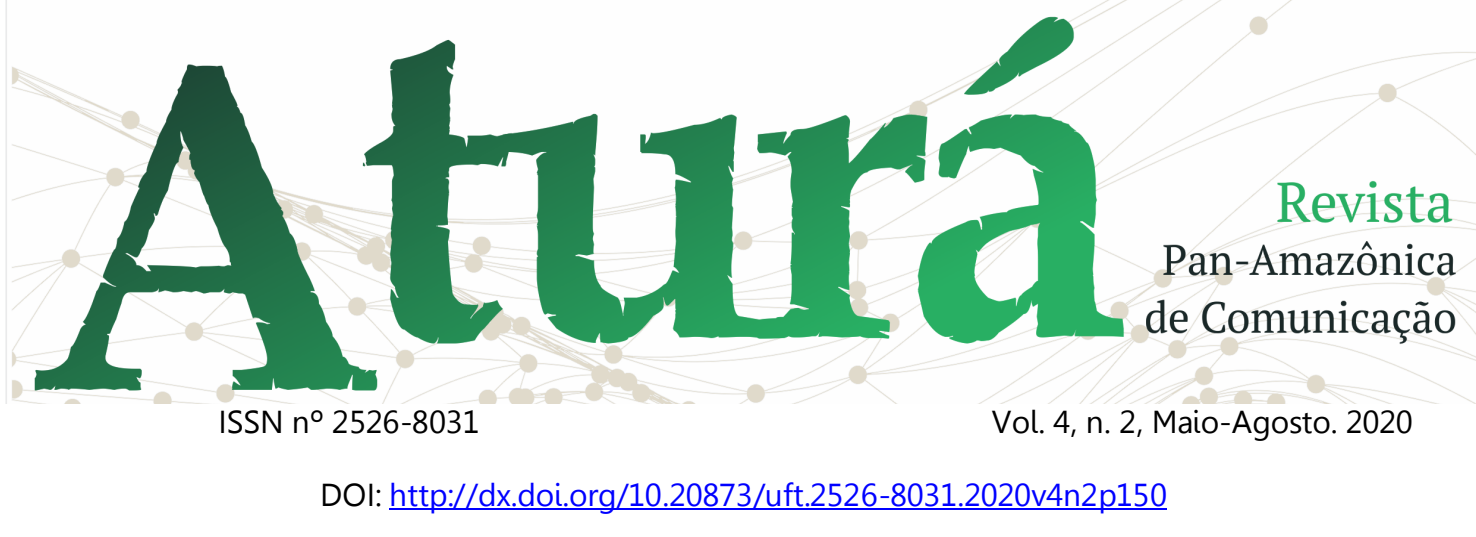

2018: Year of the Woman, in 5 Powerful Quotes foi publicado no dia 28 de dezembro de 2018, nele Salam (2018f) fala novamente a respeito da pena da maternidade, situação na qual mulheres encontram muito mais dificuldade do que os homens para conseguir uma recolocação profissional. O texto também aborda a discriminação sofrida pelas mulheres grávidas no ambiente de trabalho, principalmente as mulheres negras.

R. Kelly: Why So Many Ignored the Warning Signs é um texto que fala a respeito das acusações de abuso sexual contra o cantor R. Kelly ${ }^{21}$ e afirma que o canal Lifetime exibiu um documentário chamado: Sobrevivendo a R. Kelly (tradução nossa) que continha relatos de adolescentes que alegaram ter sido abusadas por Kelly. O texto afirma ainda que Kelly tem abusado principalmente de mulheres negras, jovens e vulneráveis e discorre sobre como a população negra sofreu para aceitar que Kelly era culpado.

${ }^{21}$ Biografia disponível em: <https://www.biogra phy.com/musician/r-kelly>. Acesso em: 22 jan. 2020.
Taking Back 'Hysterical' foi publicado em 26 de fevereiro de 2019 e falava a respeito de como o discurso das mulheres é diminuído e desmoralizado ao tachar as mulheres de histéricas, quando elas resolvem expor as suas opiniões, anseios e raivas. O texto usa como exemplo novamente $\mathrm{o}$ caso a tenista Serena Willians.

No dia 26 de março de 2019 a In Her Words publica o texto Traveling the World, While Looking Over Her Shoulder, traz relatos de mulheres que enfretaram situações de perigo ao viajarem sozinhas. "Hannah Gavios, 26, was attacked while visiting Southeast Asia on her own in 2016, causing her to tumble from a cliff and fracture her spine. The man sexually assaulted her while she lay helpless for 11 hours". Outro relato trouxe: "Vasilisa Komarova was assaulted while camping in Bolivia in 2017 and left for dead. She was in her mid-30s. The place, she had been told, was safe".

Trouxe ainda o relato de Jéssica Nabongo, que espera ser a primeira 




mulher negra a visitar todos os países do mundo.

Por último, a In Her Words publicou no dia 26 de abril de 2019 o texto Why Music Festivals Need More Beyoncés, no qual falava da importância de Beyoncé, a primeira artista negra a liderar o festival Coachela ${ }^{22}$ em seus 20 anos de história. Salam (2018) cita que no ano de 2018 mais de 100 festivais de música concordaram em buscar a paridade de gênero em até 50/50 até o ano de 2022, como parte de uma iniciativa denominada Keychange $e^{23}$.

Percebe-se que a In Her Words trouxe à tona as diversas formas de representar e de dar voz a mulher negra dentro do espaço destinado a tratar a comunicação em uma perspectiva de gênero. É pertinente ressaltar aqui, por meio de comparação metafórica, que a editoria de gênero do referido jornal abre espaço e permite que a mulher negra "rompa a máscara do silenciamento", dando voz a elas. A representatividade e

${ }^{22}$ Disponível em: <https://www.coachella.com/>. Acesso em: 22 jan. 2020.

${ }^{23}$ Disponível em: <https://keychange.eu/>. Acesso em: 22 jan. 2020. a possibilidade de essas mulheres oportunizarem às outras mulheres a consciência de democratização da comunicação é importante para a perpetuação desse direito.

Outra percepção a respeito do editorial, relacionando-o com segunda parte desta pesquisa, é a de que por meio das histórias contadas sobre e para as mulheres negras, limita-se $\mathrm{O}$ acontecimento das "histórias únicas "citadas por Adichie (2019) anteriormente. À vista disso, a importância da representatividade já citada acima, e a necessidade de pensar em uma comunicação plural e democrática.

Sendo assim, pode-se mais uma vez, abordar o conceito de interseccionalidade ao afirmar que dentro do espaço proposto pela editoria de gênero, não houve sobreposição de classe, raça e gênero para tratar de temas caros às mulheres.

No entanto, vale ressaltar que: diante do universo de 68 textos, ter apenas 14 abordando a questão da 


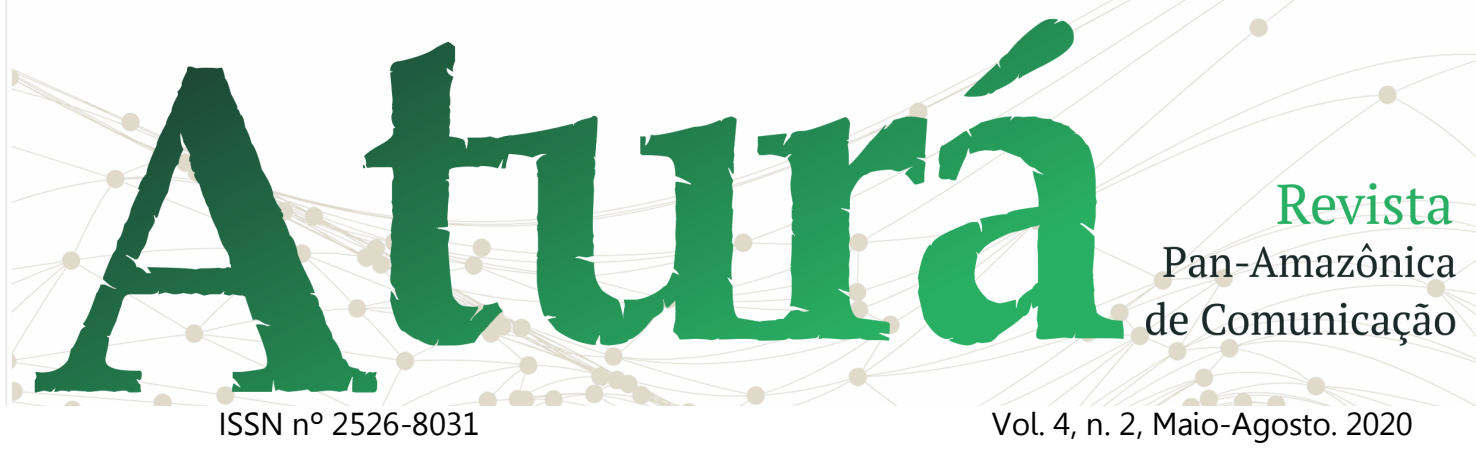

DOI: http://dx.doi.org/10.20873/uft.2526-8031.2020v4n2p150

mulher negra ainda pode ser considerado um número insuficiente, mesmo levandose em consideração o ponto de vista da interseccionalidade. Como a abordagem da mulher negra não é tratada de forma específica, e sim de uma maneira mais transversalizada; as temáticas poderiam ser mais exploradas, levando em consideração também, a inserção de uma repórter negra para fazer parte do quadro de jornalistas da editoria da In Her Words. Assim, cabe ressaltar mais uma vez a representatividade, ao sugerir nesta pesquisa, que seja delegado a uma mulher negra o papel de falar sobre as várias temáticas que oportunizem a visibilidade da raça negra.

A percepção dos direitos civis e a possibilidade de "fala" são consequência da luta das mulheres negras, por avançarem além do movimento feminista heterogêneo.

O movimento feminista negro ofereceu às mulheres uma visão mais ampla a respeito dos seus direitos na sociedade civil. A heterogeneidade branca por muito tempo atuou de forma displicente e também preconceituosa em relação a raça negra, tratando de assuntos de relevância de forma heterogênea e não dando espaço para que as mulheres negras pudessem contar as suas histórias.

Ao contar as suas próprias histórias, as mulheres negras têm o controle e a real percepção do que vai ser dito. Mais uma vez cabe aqui o conceito de lugar de fala, e do mérito de falar a respeito daquilo que se vive, e não do que se imagina.

\section{Referências}

ADICHIE, Chimamanda. O perigo da história única. 2009.

BENNETT, Jessica. Moms, They Get the Job Done. The New York Times, [S. l.], 20 abr. 2018a. In Her Words, p. sn. Disponível em: <https://www.nytimes.com/2018/04/20/u s/gender-letter-moms-they-get-the-jobdone.html>. Acesso em: 18 jan. 2020.

. Remembering New York City's First Female Cab Driver. The New York Times, [S. l.], 4 maio 2018b. In Her Words, p. sn. Disponível em: <https://www.nytimes.com/2018/05/04/u s/gender-letter-remembering-new-york- 


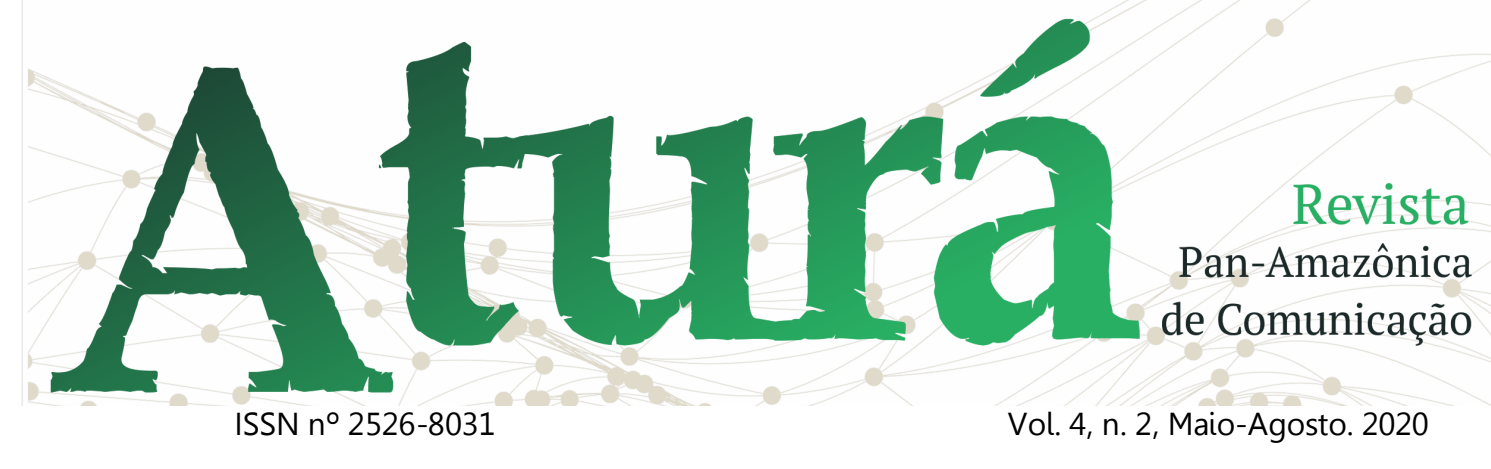

DOI: http://dx.doi.org/10.20873/uft.2526-8031.2020v4n2p150

citys-first-female-cab-driver.html>.

Acesso em: 18 jan. 2020.

BEAUVOIR, Simone de. O segundo sexo (1949). Rio de Janeiro: Nova Fronteira, 1980.

CORRÊA, Laura Guimarães et al. Entre o interacional e 0 interseccional: Contribuições teórico-conceituais das intelectuais negras para pensar a comunicação. Revista ECO-Pós, v. 21, n. 3, p. 147-169, 2018.

DAVIS, Angela. Mulheres, raça e classe. Boitempo Editorial, 2016

HAHN, Jason. The Biggest Male On-Court Meltdowns in Tennis History. People, [S. l.], 10 set. 2018. Sports, p. sn. Disponível em: $<$ https://people.com/sports/male-oncourt-meltdowns-tennis-history/>.

Acesso em: 18 jan. 2020.

HOOKS, Bell. O feminismo é para todo mundo-Políticas arrebatadoras. Tradução: Ana Luisa Libânio. Rio de Janeiro: Rosa dos Tempos, 2018.

Não sou eu uma mulher: mulheres negras e feminismo. Plataforma Gueto, 2014.

KILOMBA, Grada. Memórias da plantação: episódios de racismo cotidiano. Rio de Janeiro: Cobogó, 2019.

MEACHAM, Mike. The myth of the black matriarchy under slavery. Mid-American Review of Sociology, v. 8, n. 2, p. 23-41, 1983.
MOYNIHAN, Daniel Patrick. The Negro family: The case for national action (1965). African American Male Research, p. 1-35, 1997.

REYES, Júlia; LAGUARDIA, Adelaine. Sing a Black Girl's Song: Ntozake Shange e o Feminismo Afro-Americano. Cadernos do IL, n. 47, p. 004-020, 2013.

RIBEIRO, Djamila. Quem tem medo do feminismo negro? Editora Companhia das Letras, 2018.

. Lugar de fala. Pólen Produção Editorial LTDA, 2019.

SALAM, Maya. Meghan Markle, Our AntiPrincess Princess, Builds a Bridge. The New York Times, [S. l.], 18 maio 2018a. In Her Words, p. sn. Disponível em: https://www.nytimes.com/2018/05/18/us/ meghan-markle-princess-genderletter.html. Acesso em: 18 jan. 2020.

Hollywood Is as White, Straight and Male as Ever. The New York Times, [S. l.], 2 ago. 2018b. In Her Words, p. sn. Disponível em: https://www.nytimes.com/2018/08/02/art s/hollywood-movies-diversity.html. Acesso em: 18 jan. 2020.

When the Resistance Meets the Polls: A Historic Week for Women Politicians. The New York Times, [S. l.], 16 ago. 2018c. In Her Words, p. sn. Disponível em: https://www.nytimes.com/2018/08/16/us/ politics/women-candidates-midtermelections.html. Acesso em: 18 jan. 2020. 


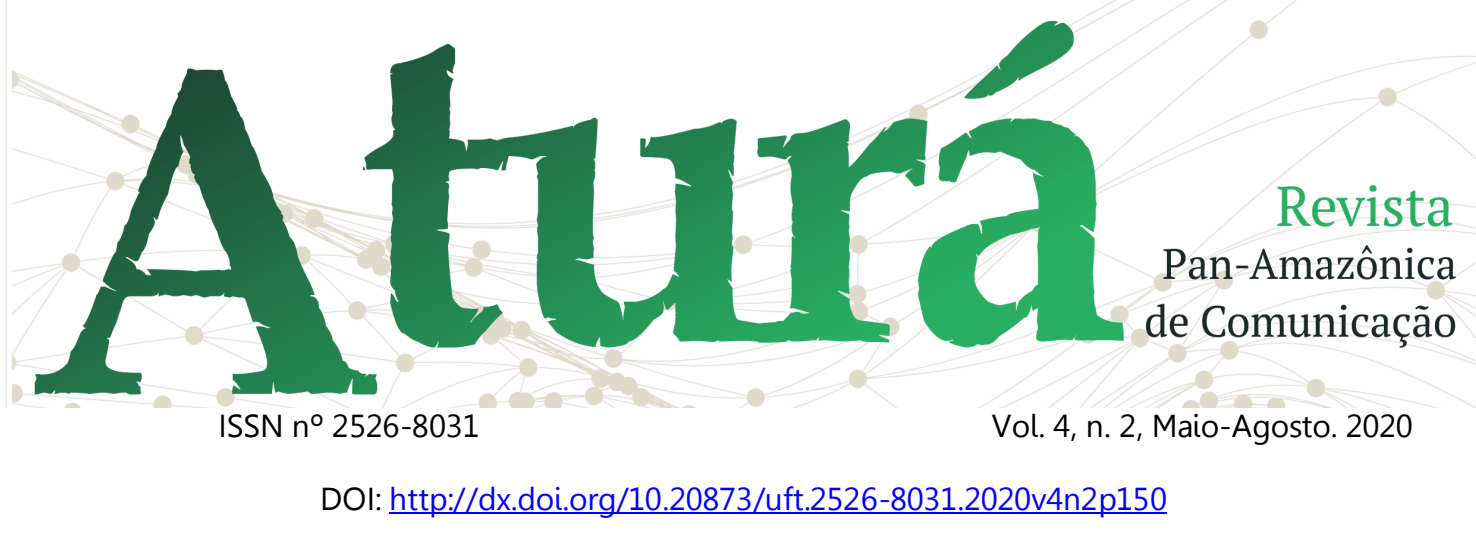

Serena's Not Alone. Women Are Penalized for Anger at Work, Especially Black Women. The New York Times, [S. l.], 13 ago. 2018d. In Her Words, p. sn. Disponivel em: https://www.nytimes.com/2018/09/13/sp orts/serena-williams-discriminationblack-women.html. Acesso em: 18 jan. 2020.

\section{Christine Blasey Ford Pushes Back:}

Here's What Might Happen Next. The New York Times, [S. l.], 21 set. 2018e. In Her Words, p. sn. Disponível em: https://www.nytimes.com/2018/09/21/us/ kavanaugh-blasey-ford-anita-hill.html.

Acesso em: 18 jan. 2020.

\section{. They Challenged the Status Quo.}

On Tuesday, They'll Find Out Who's With Them. The New York Times, [S. l.], 2 nov. 2018f. In Her Words, p. sn. Disponível em: <https://www.nytimes.com/2018/11/02/u s/elections/midterm-campaignads.html>. Acesso em: 18 jan. 2020.

\section{Why Music Festivals Need More} Beyoncés. The New York Times, [S. l.], 26 abr. 2019. In Her Words, p. sn. Disponível em:

<https://www.nytimes.com/2019/04/26/a rts/music/beyonce-coachella-womenfestivals.html>. Acesso em: 18 jan. 2020. 